\title{
Can the art of mitral valve repair become completely standardized?
}

\author{
Ehud Raanani, MD
}

\author{
From the Department of Cardiothoracic Surgery, Sheba Medical Center, Tel Hashomer, Israel. \\ Disclosures: Author has nothing to disclose with regard to commercial support. \\ Received for publication Jan 31, 2016; accepted for publication Feb 2, 2016; available ahead of print March 11, \\ 2016. \\ Address for reprints: Ehud Raanani, MD, Department of Cardiothoracic Surgery, Sheba Medical Center, \\ Tel Hashomer, 52621 Israel (E-mail: ehud.raanani@sheba.health.gov.il). \\ J Thorac Cardiovasc Surg 2016;151:1671-2 \\ $0022-5223 / \$ 36.00$ \\ Copyright (C 2016 by The American Association for Thoracic Surgery \\ http://dx.doi.org/10.1016/j.jtcvs.2016.02.006
}

Anyanwu and colleagues ${ }^{1}$ from Icahn School of Medicine at Mount Sinai Hospital, New York, retrospectively reviewed intraoperative prerepair echocardiographic studies of 668 patients who underwent mitral valve (MV) repair surgery in their department. They created a "lesion complexity score," which they divided into 3 grades: simple, intermediate, and complex. The score took into account the number and location of the up to 8 prolapsing mitral segments and other pathologic conditions, such as valve calcification, leaflet restriction and prior MV repair surgery. Anyanwu and colleagues ${ }^{1}$ found that the higher lesion score correlated directly with surrogates of technical complexity, such as longer mean cardiopulmonary bypass time, a higher number of repair techniques, and an increased need for advanced repair techniques for the more complex lesion scores. The repair rate was almost $100 \%$, even for the high-scoring "complex" lesions, and there was no difference between the groups in early adverse events and late freedom from recurrent mitral regurgitation and reoperation.

Drs Anyanwu and Adams and the rest of the team from Mount Sinai Hospital are to be congratulated for this well-designed study. They are also to be commended for their continuing efforts to educate surgeons and standardize this field of degenerative MV repair.

The main idea behind this study lies in the indisputable need worldwide to enhance the repair rates of degenerative mitral regurgitation in preference to prosthetic valve replacement surgery. By providing a classification of lesion severity and demonstrating that in a reference center even complex lesions can be safely repaired with good early and late outcomes, Anyanwu and colleagues ${ }^{1}$ hope to create a common global language that will facilitate the identification of complex repair cases and have these patients referred to centers of excellence.

Most of the several study limitations were accurately outlined in the article. Because of the retrospective nature of the study, Anyanwu and colleagues ${ }^{1}$ actually used a "reversed" lesion complexity scoring. This means that the scoring process was created by 2 surgeons according

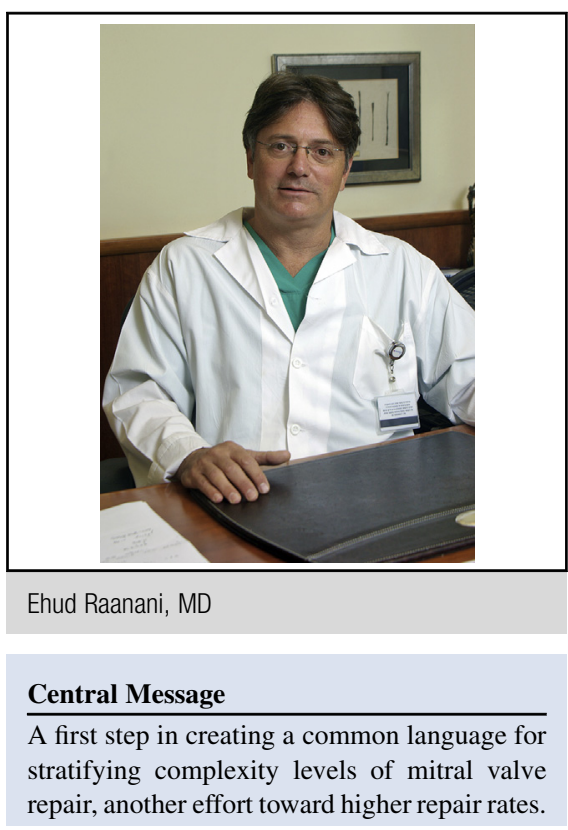

See Article page 1661 .

to their own practice, and that the scoring of each MV lesion was performed arbitrarily. This is a reasonable technique when used to evaluate and validate technical complexity in an individual surgical practice; however, I am not sure that this scoring method would be appropriate for general use and whether it could be adopted by the overall surgical and cardiology community. MV repair surgery still tends to be more of an art than an exact science. For the same specific MV lesion, different surgeons may use different repair approaches and techniques, all of which may be successful. Thus for any given particular lesion, several surgeons might use multiple repair maneuvers, making it a complex repair, whereas others might use a more simple approach. For example, in this study a patient with Barlow disease with a prolapse of $\mathrm{P} 2, \mathrm{P} 3, \mathrm{~A} 2$, and $\mathrm{A} 3$ would receive a complexity score of $6(1+1+2+2)$, which would place this patient in the complex lesion score group. The reason that this patient would receive a high lesion score is that the surgeons at Mount Sinai Hospital usually use multiple techniques, such as chordal replacement, chordal transfer, and leaflet sliding plasty for repairing this type of pathology. Other surgeons elsewhere, however, might prefer a simpler approach, such as the ring only approach or other nonresection repair techniques. ${ }^{2,3}$ In such cases, these simple repair techniques would not correlate with the proposed lesion complexity scoring. This particular method of scoring 
thus would probably not conform to the practices of other centers and settings. Further prospective studies are required to confirm such generalizations.

This study may be a first step toward a more general classification that could be applied worldwide. Its importance lies not only in its potential to achieve higher global repair rates by improved training and changes in referral patterns but also its potential to create a possible change in the timing of patient referral for MV repair. Currently, because of the relatively low general repair rates of complex mitral pathologies, many patients are referred for surgery when the disease is at an advanced stage, sometimes after myocardial and pulmonary damage has already occurred. Should stan- dardization become effective, cardiologists would feel more comfortable referring patients with complex pathologies to reference centers earlier in the progression of the disease, before irreversible damage has occurred.

\section{References}

1. Anyanwu AC, Itagaki S, Chikwe J, El-Eshmawi A, Adams DH. A complexity scoring system for degenerative mitral valve repair. J Thorac Cardiovasc Surg. 2016;151:1661-70.

2. Ben Zekry S, Spiegelstein D, Sternik L, Lev I, Kogan A, Kuperstein R, et al. Simple repair approach for mitral regurgitation in Barlow disease. J Thorac Cardiovasc Surg. 2015;150:1071-7.e1.

3. Lawrie GM, Earle EA, Earle NR. Nonresectional repair of the Barlow mitral valve: importance of dynamic annular evaluation. Ann Thorac Surg. 2009;88:1191-6. 